\title{
O Sindicalismo docente universitário da Argentina, Brasil, Colômbia, México e sua resistência à contrarreforma universitária ${ }^{1}$
}

\author{
El sindicalismo docente universitario de Argentina, Brasil, Colombia, \\ México y su resistencia a la contrarreforma universitaria
}

University labor unions in Argentina, Brasil, Colombia, México and their resistance to the university counter-reformation

\author{
Carlos Bauer ${ }^{2}$ \\ Universidade Nove de Julho (Brasil) \\ (Grupo de pesquisa GRUPHIS - HISULA) \\ Luis Paiva ${ }^{3}$ \\ Universidade Nove de Julho (Brasil) \\ (Grupo de pesquisa GRUPHIS)
}

Recepción: 30/07/2016

Evaluación:13/04/2017

Aceptación: 05/05/2017

Artículo de Reflexión

DOI: https://doi.org/10.19053/01227238.5210

\section{RESUMO}

O ensaio aborda de forma comparada alguns aspectos que estão presentes na história e trajetória dos movimentos sindicais organizados pelos professores universitários argentinos, brasileiros, colombianos, mexicanos e procura estabelecer um exame crítico do seu papel político frente aos percalços impostos

1 O presente trabalho é resultado de pesquisa comparativa financiada pelo Conselho Nacional de Ciência e Tecnologia - CNPq sobre o sindicalismo docente universitário da Argentina, Brasil, Colômbia e México.

2 Professor doutor no Programa de Pós-Graduação em Educação da Universidade Nove de Julho (PPGE) e membro do Grupo de História e Teoria do Trabalho Docente e do Educador Social (GRUPHIS) e um dos coordenadores da Rede Associativismo e Sindicalismo dos Trabalhadores em Educação (ASTE).Email carlosbauer@pesquisador.cnpq.br

3 Doutorando no Programa de Pós-Graduação em Educação da Universidade Nove de Julho e professor de História da rede municipal de Diadema, São Paulo, Brasil. Email: luispaiva64@gmail.com 
pela contrarreforma universitária neoliberal. Destacamos o conjunto de propostas em defesa do ensino superior público de acesso irrestrito, gratuito, de qualidade e autogovernada sob o princípio da autonomia universitária. Igualmente foram consideradas as formas de organização, bandeiras de luta, principais enfrentamentos e movimentos reivindicatórios por melhores remunerações e condições de trabalho, particularmente contra a precarização do trabalho. O presente texto é resultado da revisão bibliográfica sobre a temática do sindicalismo docente universitário, em aportes teóricos e metodológicos desenvolvidos por pesquisadores que atuam na Rede Associativismo e Sindicalismo dos Trabalhadores em Educação (ASTE), em materiais produzidos pelas próprias entidades sindicais/associativas docentes universitárias dos países visitados, documentos oficiais dos governos, instituições universitárias ou organismos multilaterais que reconhecidamente influenciam nas políticas educacionais para o ensino superior, como o Banco Mundial, e principalmente em entrevistas que nos foram concedidas por professores das instituições públicas universitárias que participam da vida destas entidades e de suas categorias profissionais.

Palavras-chave:Argentina; Brasil; Colômbia; México; contrarreforma universitária; sindicalismo docente universitário, Revista Historia de la Educación Latinoamericana.

\section{RESUMEN}

El ensayo aborda de forma comparada algunos aspectos que están presentes en la historia y trayectoria de los movimientos sindicales organizados por los profesores universitarios argentinos, brasileños, colombianos, mexicanos ybusca establecer un examen crítico de su papel político frente a los percances impuestos por la contrarreforma universitaria neoliberal destacando propuestas en la defensa de la enseñanza superior de acceso irrestricto, gratuito, de calidad y con respecto a la autonomía universitaria, así como sus formas de organización, banderas de lucha $y$ principales enfrentamientos y movimientos reivindicatorios por mejores remuneraciones y condiciones de trabajo, particularmente contra la precarización del trabajo. El presente texto parte de la revisión bibliográfica sobre la temática del sindicalismo docente universitario, en aportes teóricos y metodológicos desarrollados por la red Associativismo y Sindicalismo de los Trabajadores en Educación (ASTE), en materiales producidos por las propias entidades sindicales / asociativas docentes universitarias de los países visitados, documentos Oficiales de los gobiernos $\mathrm{u}$ organismos multilaterales que reconocidamente influyen en las políticas educativas para la enseñanza superior, como el Banco Mundial, y principalmente en entrevistas que nos han sido concedidas por profesores de las instituciones públicas universitarias que participan en la vida de estas entidades.

Palabras clave: Argentina; Brasil; Colombia; México; contrarreforma universitaria; sindicalismo docente universitario, Revista Historia de la Educación Latinoamericana. 


\section{ABSTRACT}

This work discusses in a comparative way some aspects of history and trajectory of the labor union movements organized by Argentinian, Brazilian, Colombian and Mexican university professors and intends to establish a critical examination of their political role regarding the mishaps imposed by the neoliberal university counter-reformation. They stand out proposals in the defense of higher education of unrestricted, free, and quality access. It also highlights the struggle for university autonomy, as well as its forms of organization, fight flags, main clashes and demands for better salary and working conditions, particularly against the precarious employment. This text is made on the basis of the bibliographical review on the subject of university labor union, it also takes into account the theoretical and methodological contributions developed by the network Associativism and Syndicalism of the Workers in Education (known is Spanish as ASTE), materials produced by the university labor unions / associations in the countries visited, official documents of the governments or multilateral organizations that are known to influence education policies for higher education, such as the World Bank, and mainly, interviews granted by professors who partake in the life of these public universities.

Keywords: Argentina; Brazil; Colombia; Mexico; University counter-reformation; University labor union, Journal History of Latin American Education.

\section{INTRODUÇÃO}

Lançando mão de entrevistas realizadas com os seus protagonistas, revisão bibliográfica, documentos oficiais, fontes secundárias, documentos e materiais produzidos pelas próprias entidades e outros agentes, o ensaio aborda de forma comparada alguns aspectos que estão presentes na história dos movimentos sindicais organizados pelos professores universitários argentinos, brasileiros, colombianos, mexicanos e procura estabelecer um exame crítico do seu papel político frente aos percalços impostos pela contrarreforma universitária neoliberal. Com recursos financeiros fornecidos pelo Conselho Nacional de Ciência e Tecnologia - CNPq, os autores visitaram e conheceram in loco a realidade social e política dos países mencionados, travaram contato com os professores universitários que participam da vida sindical de sua categoria e tiveram oportunidade de conhecer algumas instituições universitárias bem como reunir fontes primárias e secundárias que utilizaram na redação dos manuscritos. 


\section{Elementos da gênese do sindicalismo docente universitário}

Ao contrário da América Hispânica, onde foram criadas instituições de ensino, denominadas como universidades, muito antes da independência Peru (1551), México (1553), Colômbia (1580), e Argentina (1623) ${ }^{4}$ - no Brasil prevaleceram os colégios jesuítas, que se dedicavam à reprodução dos quadros da própria Ordem e à instrução dos filhos da burguesia, com cursos, que mesmo podendo ser considerados como superiores, Filosofia e Teologia, não foram nunca equiparadas aos das instituições da metrópole.

Cunha $^{5}$ (2007a, p.13) atribui esse traço distinto do império português à política de reforçar vínculos de dependência da elite colonial em relação à metrópole. Somente na década de 1920 foram criadas as três primeiras e duradouras universidades estatais no Brasil: a Universidade do Rio de Janeiro (1920); a Universidade de Minas Gerais (1927); a Universidade Tecnológica de Porto Alegre (1928).

Não obstante, o sindicalismo docente universitário é um fenômeno quase coincidente nos quatro países mencionados, surgindo durante a década de 1970, ainda que houvesse anteriormente outras formas de organização. Para o professor argentino Néstor Correa o sindicalismo docente universitário tem base na massificação da educação universitária ocorrida a partir do pós-Segunda Guerra, mas destaca que esta expansão ocorreu com uma mudança do setor social que tradicionalmente compunha o ensino superior:

Com ritmos, situações e heranças diferentes nos distintos países e regiões se produz a partir do segundo pós-guerra um enorme crescimento, uma massificação da educação universitária, em princípio fundamentalmente da pública. Este processo abarca Europa, América Latina e Estados Unidos em distintos graus e a partir da década de 1960 intensifica-se com uma amplitude que não se havia dado antes. Esta é a base material sobre a qual se apoia o surgimento do sindicalismo docente, com um caráter global, como assim também da massificação do movimento estudantil [...] outros setores sociais com outras necessidades entram na universidade. Isso tem um impacto nos estudantes, e tem um impacto na realidade social do docente ${ }^{6}$.

Para o Brasil, Cunha (2007) ressalta que o ritmo de industrialização e monopolização da economia, que se impôs a partir dos anos 1950 com o ingresso de capitais estrangeiros, ao mesmo tempo em que introduzia novos produtos e formas de organização do trabalho, desestruturou o sistema produtivo nativo e restringiu o desenvolvimento dos pequenos negócios na área industrial. Tais transformações teriam levado os setores médios a recorrerem ao ensino superior

4 Universidade Nacional Maior de San Marcos, no Peru (1551); Real e Pontifícia Universidade de México (1553); Universidade Santo Tomas, Colômbia (1580); Universidade Jesuítica de Córdoba, Argentina (1623).

5 Cunha, Luiz Antonio A universidade crítica: O ensino superior na república populista. 3ed. (São Paulo: Editora Unesp, $2007 \mathrm{~b}), 216$.

6 Conadu Historica. Federação Nacional de Docentes, Investigadores e Criadores Universitários. El sindicalismo docente universitario: Aportes a la Reconstrucción colectiva desde CONADU HISTORICA (1971-2011). (Buenos Aires: Ediciones Conadu Historica e CTA Central de Trabalhadores da Argentina, 2011), 149. 
para ascender socialmente, seja para ingressar como trabalhador especializado nas novas empresas, estabelecendo-se como profissional liberal ou ainda como quadro técnico do Estado. Nas palavras de Cunha,

No Brasil surgiram mecanismos que tornaram o ensino superior mais acessível para esses setores sociais. Um deles foi a gratuidade que se estabeleceu na prática no setor público, uma vez que as várias taxas e anuidades deixaram de ser atualizadas pela inflação, a partir de 1950, tornando-se praticamente simbólicas com decorrer do tempo e desvalorização da moeda Cunha7.

Na Argentina, em 1949, Perón havia estabelecido o acesso irrestrito ao ensino superior e criado a Universidade Operária, atualmente denominada de Universidade Tecnológica Nacional (UTN).

Osurgimento das entidades sindicais indica um processo de profissionalização da atuação docente, a partir do crescimento do número de indivíduos que passou a ter na educação sua principal, ou única, fonte de rendimentos e resultou no estabelecimento de necessidades específicas de um coletivo (remuneração, progressão na carreira, condições de trabalho), bem como a formação de uma identidade e pertencimento a um agrupamento.

Mesmo na UNAM, onde a organização de trabalhadores técnicoadministrativos e de docentes é tão antiga quanto o reconhecimento da “autonomia universitária", de $1929^{8}$, foi só a partir do início da década de 1970, que a luta pelo reconhecimento da organização sindical ganhou ímpeto. Está associada não só à expansão da cobertura do ensino superior, mas também às mobilizações estudantis que resultaram em enfrentamentos com as forças repressivas em 1968 na Praça das Três Culturas (Tlatelolco) e em 1971 nas proximidades da Benemérita Escola Nacional de Maestros, também na Cidade do México.

O epicentro desse processo de organização foi a UNAM e deu-se com o Sindicato de Trabalhadores e Empregados da UNAM (STEUNAM) seguido de vários conflitos e uma longa greve (1972/1973). Pouco depois, em 1974, os docentes fundam o Sindicato do Pessoal Acadêmico da UNAM (SPAUNAM).

Em 1977, em um período também marcado por uma difícil greve, os dois sindicatos se unificam dando origem ao Sindicato dos Trabalhadores da UNAM (STUNAM), um sindicato misto (trabalhadores acadêmicos e administrativos) que se constituiu na principal entidade do movimento sindical universitário mexicano.

7 Cunha, Luiz Antonio. A universidade crítica: O ensino superior na república populista. 3ed. (São Paulo: Editora Unesp, $2007 \mathrm{~b}), 76$.

8 Trabalhadores administrativos: União de Empregados da Universidade Nacional Autônoma do México (1929); Sindicato de Empregados e Operários da UNAM (1933); Sindicato de Trabalhadores da UNAM (1945);Sindicato de Empregados e Operários da UNAM (1961); Associação de Trabalhadores Administrativos da UNAM (1966); Sindicato de Trabalhadores e Empregados da UNAM (1971); Trabalhadores acadêmicos: União de Empregados, Professores e Operários da UNAM (1937); Federação de Professores Universitários da UNAM (1938); Associação de Professores Universitários do México (1950); Sindicato de Professores da UNAM (1964); Sindicato Independente de Professores da UNAM (1972); Sindicato de Pessoal Acadêmico da UNAM (1974); Associação de Agrupações do Pessoal Acadêmico da UNAM (1974). In: Basurto, Jorge. Los movimientos sindicales en la UNAM. (México D.F.: UNAM/Instituto de Investigações Sociais, 1997), 289. 
Há na UNAM ainda a Associação Autônoma de Pessoal Acadêmico da UNAM (AAPAUNAM), fundada também em 1974 e que é responsável pela representação majoritária dos seus acadêmicos, mas com uma postura menos crítica e sem desempenhar em nível nacional o mesmo papel do STUNAM.

Além da conjuntura autoritária e do descontrole inflacionário, a luta pelo reconhecimento do direito à organização sindical também foi marcada por fatores próprios da categoria e das instituições de ensino superior no México: a) a resistência das autoridades acadêmicas e mesmo de setores mais conservadores de professores de se reconhecerem inseridos em relações trabalhistas; b) a relação da autonomia universitária e as especificidades do movimento sindical mexicano.

Assim como no México, a organização do sindicalismo docente universitário na Argentina também foi antecedida por uma forte comoção social que teve o movimento estudantil como fulcro, o Cordobazo, em 1969. A primeira paralisação docente ocorreu em março de 1971 na Universidade Nacional do Sul (UNS) no Departamento de Matemática. Foram ajudantes e assistentes que tiveram o apoio de professores ${ }^{9}$. Segundo o professor e militante sindical Carlos Mosquera a organização sindical universitária e o momento social e histórico vivido no contexto argentino estavam ligados:

Neste momento [1971] para a sociedade argentina ser trabalhador era um orgulho. Que o docente universitário começasse a sentir-se um trabalhador é o que fez que inicie a gestar-se em movimento a organização nas Exatas do ano de 71. O eixo foi esta ideia que começou a surgir nas maiorias docentes, ademais do que tinham em mente o Cordobazo, o Rosariazo, e todos os levantamentos em distintas províncias do país ${ }^{10}$.

Ainda em 1971 teve início a organização da Associação de Docentes e Investigadores da Faculdade de Ciências Exatas (ADIFCE) na Universidade de La Plata, que em 1973, impulsionou a criação da Associação de Docentes da Universidade de La Plata (ADULP). Nos três anos seguintes os docentes universitários criaram várias associações por faculdades e universidades e que se agruparam na Confederação Nacional de Trabalhadores da Educação da República Argentina (CTERA), que congregava professores de todos os segmentos. O fim da ditadura de Ongania (1966-1970) e o retorno de Perón (1973) acelerou o processo de organização sindical.

Com o golpe de 1976 as organizações foram desmanteladas, muitos militantes foram afastados, demitidos, presos, torturados, mortos ou desapareceram tragicamente. A reorganização do sindicalismo docente principia em 1983 acompanhando a redemocratização da sociedade e em outubro de 1984

9 Nota dos autores: Na Argentina as universidades estão organizadas em geral por cátedra e um professor coordena o trabalho de outros professores que assumem diversas designações (adjuntos, associados, práticos, ajudante de primeira, ajudante de segunda) que são responsáveis pelas aulas e aplicação de exames.

10 Conadu Historica. Federação Nacional de Docentes, Investigadores e Criadores Universitários. El sindicalismo docente universitario: Aportes a la Reconstrucción colectiva desde CONADU HISTORICA (1971-2011). Buenos Aires: Ediciones Conadu Historica e CTA (Central de Trabalhadores da Argentina), 2011, 149. 
foi criada a Coordenadora Nacional de Docentes Universitários (CONADU) que em abril do ano seguinte passou à categoria de Confederação.

$\mathrm{Na}$ Colômbia, país marcado pela existência de guerrilhas desde a década de 1960 e ação de grupos paramilitares, onde os militantes sindicais e de movimentos sociais transformaram-se em alvos militares, a criação da Associação Sindical dos Professores Universitários (ASPU), também esteve associada aos processos de mobilização estudantil ocorridos no início da década de 1970. Sobre essa associação o professor da Universidade Nacional (Bogotá), Juan de La Cruz Sanchez ${ }^{11}$ observa que a "ASPU existe há uns 45 anos. É da década de 1970. Antes o que havia eram associações de professores universitários, mas não sindicatos. Eram associações civis, que inclusive tinham de ter registro na câmara de comércio. Eram regidas pela lei de comércio e não de trabalho". (Entrevista concedida aos autores)

O professor colombiano Gonzalo Arango Jimenez, da Universidade Tecnológica de Pereira (UTP), presidente da Federação Nacional de Professores Universitários (FENALPROU) e da seção sindical da ASPU da UTP, reforça em seu depoimento o vínculo entre movimento estudantil e docente:

E é nesse período, quando estudei nesta universidade [UTP], que vivi o ascenso do movimento estudantil de 1971. Iniciei meus estudos em 1968 e me graduei em 1974. Na metade desse período participo ativamente como dirigente na universidade no movimento nacional universitário em 1971. Antes, quando eu ingressei na universidade já há toda uma agitação política e, portanto, influência ideológica e política da França, do México ${ }^{12}$.

No Brasil o processo de organização sindical também é um fenômeno da década de 1970. A Associação Nacional dos Docentes do Ensino Superior (ANDES) foi criada em 1981 e só pode converter-se em sindicato, com suas respectivas seções sindicais, depois da Constituição em 1988.

Nas palavras de Ridenti ${ }^{13}$ (1995), desde meados da década de $1970^{14}$ foram sendo criadas associações por professores universitários, que começaram a estabelecer contatos por meio de encontros paralelos que ocorriam durante as reuniões da Sociedade Brasileira para o Progresso da Ciência (SBPC). Em julho de 1978, na 30ª reunião da SBPC realizada na Universidade de São Paulo (USP), a Associação dos Docentes da Universidade de São Paulo (Adusp) teria fixado

11 Professor Juan, de La Cruz Sanchez, da Universidade Nacional (Bogotá), Entrevista concedida a Bauer, Carlos, Bogotá, Colômbia.

12 Professor Gonzalo Arango Jimenez, da Universidade Tecnológica de Pereira (UTP), Entrevista concedida a Paiva, Luís, Pereira, Colômbia.

13 Ridenti, Marcelo Siqueira. Andes: representação política e sindical de professores universitários. Cadernos de Pesquisa Fundação Carlos Chagas. N.93, pp 72-80. São Paulo, maio 1995. Disponível in:< http://publicacoes.fcc.org.br/ojs/index.php/cp/article/ view/851>. Acessado em 20/01/2016. 9:24h. 73.

14 Há, no entanto, registro de associações de professores universitários anteriores à década de 1970, como afirma Donatoni (2006, 6157): a Associação de Professores da Universidade Federal do Paraná (APUFPR), fundada em 1960, a Associação dos Professores da Universidade Rural do Estado de Minas Gerais (APUREMG), criada em 1963 e que hoje se denomina Associação dos Professores da Universidade Federal de Viçosa (ASPUV), e a Associação dos Professores Universitários de Santa Maria (APUSM), de 1967, servem como exemplo. 
um cartaz convocando uma reunião de membros de associações presentes ao evento.

Nas instituições privadas de ensino superior também ocorreu um processo de organização, mas a perseguição das administrações se fez implacável e os militantes foram perseguidos e demitidos, dificultando que este importante segmento acompanhasse no mesmo ritmo a organização dos docentes das universidades públicas, com exceção de algumas poucas instituições confessionais.

A partir do encontro na USP foram realizados três Encontros Nacionais de Associações Docentes (os ENAD): 1979 em São Paulo, em 1979; João Pessoa, em 1980; e Campinas, em 1981. Em sequência ao término do III ENAD foi realizado de 17 a 20 de fevereiro o Congresso Nacional dos Docentes do Ensino Superior, quando foi fundada a ANDES.

Também no caso do Brasil a organização sindical docente universitária está associada à formação de uma camada de ativistas, oriundos do movimento estudantil da década de 1960. Nas palavras do professor Sadi Dal Rosso da Universidade Nacional de Brasília (UnB),

[...] dez anos depois, nos anos 70, muitos dos professores eram provenientes desses grupos estudantis, dos anos 67/68, e em termos de pesquisa essa vinculação é muito bonita, e em São Paulo isso é fácil de fazer junto a atuações dos anos da constituição do Andes, e você retornar o que faziam antes nos anos 60, muitos eram participantes do movimento estudantil dos anos 60. (Entrevista concedida aos autores).

O sindicalismo docente universitário nos países mencionados apresenta como traço comum a organização mais horizontal, uma vez que surgiu da representação nos locais de trabalho. Talvez, por isso, apresente altíssimas taxas de sindicalização se comparadas a outras categorias de seus respectivos países.

Outro elemento foi sua contribuição, para a redemocratização e/ou fortalecimento das instituições democráticas em seus contextos históricos. As pautas contidas nos diversos materiais produzidos por estas entidades sindicais estavam associadas a três eixos: luta pela democratização da sociedade; defesa da universidade pública, de qualidade e acesso irrestrito; questões corporativas (salários, planos de carreira, condições de trabalho).

NoBrasil, Argentina e Colômbia esse processo de organização sindical resultou na formação de entidades nacionais com seções sindicais nas universidades. No México, a luta pelo reconhecimento sindical foi vitoriosa, mas a criação de uma organização nacional foi frustrada pelas autoridades universitárias e governamentais prevalecendo sindicatos por instituições. 


\section{Contrarreforma universitária neoliberal}

O documento que melhor traduziu o ensino superior na ótica neoliberal foi La Enseñanza Superior. Las lecciones derivadas de la experiencia ${ }^{15}$ elaborado pelo Banco Mundial (BM), em 1994 (utilizamos a versão em espanhol de 1995). Caracterizava que o ensino superior vivia uma crise em escala mundial devido ao aumento da procura de vagas. Entre 1974 e 1994 o ensino superior teria sido o segmento educacional com maior aumento (Banco Mundial, 1995, p.18) superando o crescimento econômico e os recursos orçamentários disponíveis.

Responsabilizava o modelo estatal pela deterioração da qualidade no ensino superior e a não criação de vagas, cursos e instituições necessárias para a formação de mão de obra qualificada e apresenta uma lógica assentada nas premissas do pensamento liberal: um custo maior dos estudantes do setor público em relação ao privado, o "baixo" número de estudantes por professor, o nível de desistências (evasão) e o custo da assistência estudantil ${ }^{16}$.

Para o BM seriam investimentos não apenas ineficientes, mas regressivos, pois beneficiariam as camadas sociais com maior poder aquisitivo, mas ao invés de apresentar propostas que apontassem no sentido do acesso irrestrito, $\mathrm{o}$ documento propunha transferir para as instituições privadas o ensino superior e a adoção de mecanismos de mercado para as públicas onde isso não fosse possível. De direito, a educação passava a "serviço" e constituía-se um novo nicho para a exploração capitalista.

Conforme Sguissardi em 1986, no documento Financing education in developing countries: an exploration of policy options o BM já defendera a tese do maior retorno social e individual dos investimentos em educação básica que o dos investimentos em educação superior. Os investimentos na educação básica assegurariam redução das desigualdades sociais e elevação de renda dos setores mais vulneráveis da sociedade, portanto, o ensino superior não seria prioritário e inclusive não deveria demandar maiores investimentos.

[...] a realidade fiscal na maioria dos países em desenvolvimento indica que melhoramentos da qualidade e o aumento das matrículas no ensino pós-secundário, podem ser obtidos com pouco ou nenhum aumento do gasto público. $B M^{17}$.

Para alcançar estes objetivos o BM estabeleceu quatro eixos:

- Fomentar a maior diferenciação das instituições, incluído o desenvolvimento de instituições privadas;

15 Banco Mundial. La enseñanza superior: Las lecciones derivadas de la experiência. Washington: 1995 (versão em espanhol). Disponível $\mathrm{em}:<$ http://firgoa.usc.es/drupal/files/010-1344Sp.pdf>. (Acessado em: 05 de mar.de 2015), 23:19.

16 Banco Mundial. La enseñanza superior: Las lecciones derivadas de la experiência. Washington: 1995 (versão em espanhol). Disponível em: < http://firgoa.usc.es/drupal/files/010-1344Sp.pdf>. (Acessado em: 05 de mar.de 2015), 22.

17 Sguissardi, Valdemar. Universidade brasileira no século XXI: desafios do presente. (São Paulo: Cortez Editora, 2009), 341. 
- Proporcionar incentivos para que as instituições públicas diversifiquem as fontes de financiamento e a estreita vinculação entre o financiamento fiscal e resultados;

- Redefinir a função do governo no ensino superior;

- Adotar políticas que estejam destinadas a outorgar prioridade aos objetivos de qualidade e equidade.

Tais diretrizes gerais coadunavam com o reordenamento do capitalismo mundial, e materializaram-se em cada país conforme a realidade histórica e política, estimulando os traços locais que mais se aproximavam da proposta sugerida.

Não por acaso, as mudanças propostas pelo BM atentavam contra as bases do Reforma Universitária de Córdoba, ocorrida em 1918 na Argentina. Como destaca Leher,

Não é casual que a ofensiva neoliberal dos anos 1990 objetivou destruir todos os fundamentos dos reformistas: a gratuidade, o governo democrático e o pluralismo politico, a autonomia, a liberdade de pensamento e de expressão, garantidas por cátedras paralelas e pelo ingresso por meio de concurso público, o co-governo, o acesso universal, a natureza pública dos processos institucionais ${ }^{18}$.

Conceituamos as propostas da reforma universitária neoliberal conduzida pelos diferentes governos latino-americanos, como contrarreforma neoliberal, que significa um retrocesso para as instituições públicas e a comunidade universitária, ao mesmo tempo em que reforça a dependência econômica, política e cultural dos países latino-americanos em relação ao domínio das grandes corporações e suas matrizes nos países desenvolvidos.

\section{Da resistência e seus protagonistas}

Tal como Gentili e Suárez, percebemos que um elemento comum nas investigações sobre o sindicalismo docente, é a predominância de estudos de caráter nacional. Esse traço seria uma decorrência da dimensão nacional dos conflitos, que incidem sobre a produção acadêmica, não obstante as reformas educacionais serem tributárias das recomendações de organismos internacionais. Constata-se que, enquanto o capital financeiro e seus agentes transitam e se articulam na esfera global, os trabalhadores reagem e resistem na dimensão nacional, na qual as políticas consubstanciam-se em ataques à educação pública e aos direitos dos trabalhadores.

A Colômbia apresenta uma literatura muito escassa sobre o sindicalismo docente universitário. $\mathrm{O}$ tema predominante nas Ciências Humanas são os conflitos armados, um fato compreensível quando nos inteiramos que o

18 Leher, Roberto. Reforma Universitária de Córdoba, noventa anos. Um Acontecimento Fundacional para a Universidade Latinoamericanista. Disponível in: http://biblioteca.clacso.edu.ar/ar/libros/grupos/reforAboit/07leher.pdf. (Acesso em 06/09/2015). 
sindicalismo daquele país corresponde a $0,0002 \%$ do total mundial, mas foi responsável por $60 \%$ dos casos de assassinatos de sindicalistas ocorridos entre 1986 e 2013 (Central Unitária dos Trabalhadores, 2015). Neste período, um sindicalista colombiano foi morto a cada três dias e a taxa de sindicalização despencou de $14 \%$ para $3,9 \%$.

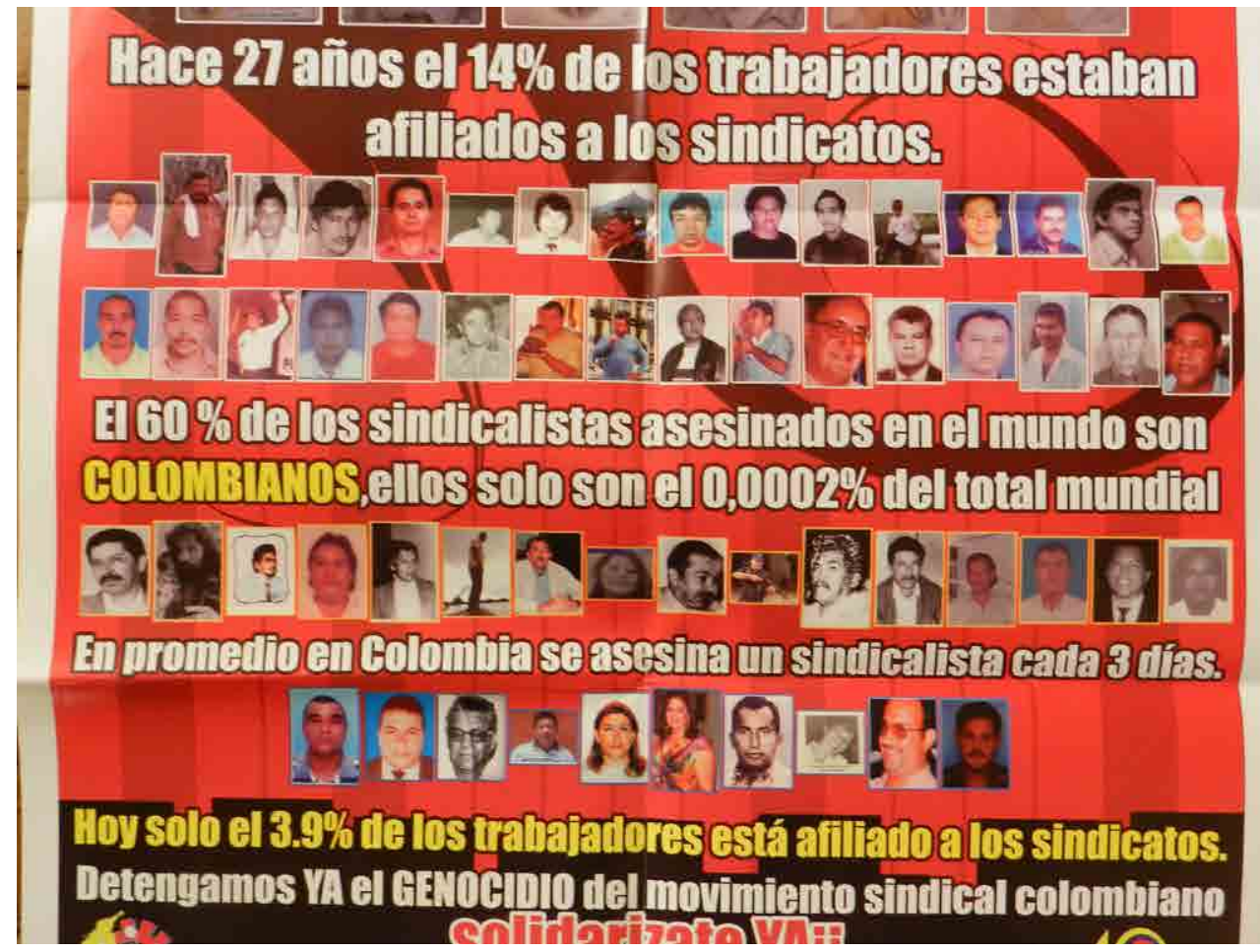

Cartaz da Central Únitária dos Trabalhadores da Colômbia, sobre a vitimização do movimento sindical ${ }^{19}$.

Valencia e Ospina ${ }^{20}$ em seus trabalhos, indicam que dos 2.870 sindicalistas colombianos assassinados entre 1977 e 2011, 889 eram professores, militantes de base da Federação Colombiana de Docentes (FECODE) o que corresponde a $31 \%$ do total.

O dia 25 de agosto foi instituído como o dia do Professor caído. A data é uma forma de denunciar o assassinato dos professores, exigir a apuração dos fatos e a punição dos responsáveis. Faz referência ao assassinato de três professores no dia 25 de agosto de 1987: Luis Felipe Vélez, presidente da Asociación de Institutores de Antioquia (Adida) seção da FECODE, e dois professo-

19 Central Unitária dos Trabalhadores (CUT). Cartaz. Documento iconográfico com denúncia sobre mortes, assassinatos e torturas de militantes sindicais. 2015. Bogotá. Acervo dos autores.

20 Valencia, Léon y Juan Carlos Celis Ospina. Sindicalismo asesinado: reveladora investigación sobre la guerra contra los sindicalistas colombianos. (Cota: Random House Mondadori, 2012), 253. 31. 
res universitários: Héctor Abad Gómez, presidente da seção de Antioquia do Comitê Permanente pela Defesa dos Direitos Humanos e fundador da Associação de Professores da Universidade de Antioquia (Asoprudea) e Leonardo Betancur, vice-presidente da Associação Médica de Antioquia. Infelizmente, ainda há o dia do "Estudante caído" celebrado em 8 e 9 de junho.

No México, a fragmentação da organização sindical, imposta desde o governo central, supostamente em defesa da "autonomia universitária", também se evidencia como um obstáculo à realização de pesquisas nacionais sobre o sindicalismo docente universitário. O STUNAM possui um importante acervo no Centro de Investigações Históricas do Sindicalismo Universitário (CIHSU), mas tem como foco a história sindical dos trabalhadores da UNAM.

Brasil e Argentina dispõem de uma literatura mais ampla sobre o tema, com significativa participação das próprias entidades sindicais, mas também restrita aos conflitos nacionais.

Em todos estes países os governos promoveram revisões legais ao longo das décadas de 1990 e 2000 para implantar as reformas:

- Colômbia - criação da Lei 30, específica para o ensino superior, em 1992, e tentativa de sua reformulação em 2011, que foi derrotada pela resistência dos estudantes colombianos que organizaram a Mesa Ampla Nacional Estudantil (MANE) em colaboração com o movimento sindical docente;

- Argentina - reforma constitucional em 1994 e aprovação no ano seguinte da Lei do Ensino Superior (n⿳0 24.521), que também contou com a resistência do movimento estudantil e da CONADU;

- México - reforma constitucional em 1993, que no artigo $3^{\text {o }}$ restringiu a responsabilidade do Estado à educação básica;

- Brasil - a aprovação da Lei de Diretrizes e Bases da Educação (Lei 9.394/96) e do Plano Nacional de Educação (PNE), e vários decretos e leis concernentes ao ensino superior sobre os quais o ANDES empenhou esforços juntamente com outras entidades sindicais, estudantis e acadêmicas para barrar propostas neoliberais e apresentar um projeto próprio. Na década de 2000 novas leis que abordaremos mais à frente.

Também foram criados organismos e entidades de avaliação das instituições universitárias que sustentam como missão a modernização do ensino superior, mas que através do condicionamento de verbas a resultados, impõem formas de organização e de funcionamento baseadas em modelos empresariais, direcionando a criação de cursos, disciplinas e pesquisas em função das necessidades dos mercados. Como avalia o próprio Banco Mundial em documento de 1998 de balanço sobre as reformas universitárias:

À medida que as universidades e os sistemas de ensino superior vão prestando mais atenção a questões como as boas práticas de gestão de pessoal, aos problemas de liquidez, a posição no mercado, a diversificação de produtos e a responsabilidade, 
seu aspecto será mais "privado", ainda quando sejam de propriedade estatal, recebam considerável apoio fiscal e se declarem abertamente "públicos" em sua missão. ${ }^{21}$ (tradução nossa).

O traço mais perverso é o estímulo às formas de trabalho com vínculo precário, com professores sem estabilidade, pela ausência de concursos, e que são forçados a trabalhar em várias instituições e passaram a ser conhecidos como "professores táxis". Nas universidades públicas da Argentina, Colômbia e México, que concentram a maior parte das matrículas do ensino superior, estas formas de contratação precária apresentam-se como majoritárias em relação aos professores de carreira. No Brasil, onde o setor privado abarca a maioria das matriculas (70\%), essas formas de contratação são minoritárias nas instituições públicas, mas vêm crescendo.

Os docentes precarizados só podem dedicar-se ao ensino, não participam de linhas de pesquisa e extensão, não dispõem de espaços e tempo para atender ou orientar os alunos, não estão envolvidos na elaboração dos projetos dos departamentos e mesmo da vida acadêmica da instituição. Tampouco podem compor o colégio eleitoral que escolhe a autoridade universitária e, não raro, têm vetado o direito à sindicalização. Chegam, ministram sua aula e se vão.

Essa dita flexibilidade de contratação laboral assume várias formas nestes países e está na base da ampliação do número de matrículas. No México, devido à liberdade que gozam as autoridades universitárias para celebrar acordos e estabelecer formas de contratação, as denominações e condições de trabalho são diversas. Na UNAM há os chamados professores de "asignatura", contratados por semestre letivo para uma disciplina.

Nesta instituição apenas $28,5 \%$ dos docentes possuem tempo completo enquanto que os professores por disciplina ou horas são 71,5\%. Na folha de pagamento da desta instituição - 46,6\% do orçamento em 2008 - 30\% correspondem aos professores de tempo completo e $16,6 \%$ aos precarizados ${ }^{22}$.

Em 2014, dos 16.522 docentes da Universidade de Guadalajara (UdeG), a segunda maior universidade do México, 9.298 eram professores de asignatura $(56,3 \%)$ e destes, apenas 1\%, (97 docentes) tinham contratos definitivos ${ }^{23}$. Há ainda professores por honorários, como no caso da Universidade Autônoma de Queretáro (UAQ), relatada pelo professor José Luís Álvares Hi-

21 Johnstone, D.Bruce, Alka Arora y William Experton. Financiamiento y gestión de la enseñanza superior: Informe sobre los progresos de las reformas en el mundo. Washington, D.C. 1998. Disponível em: < http://wwwds.worldbank.org/external/default/ WDSContentServer/WDSP/IB/2012/11/13/000425962_20121113172945/Rendered/PDF/NonAsciiFileName0.pdf >. Acessado em 10/12/2015. 16:45h.

22 Lechuga, Maria Teresa y Arturo Ramos. Magister Changarrization: los nuevos sujetos académicos y el trabajo precario em la educación superior. 2. ed. (México D.F.: STUNAM/Red Tap/Cultura, Trabajo y Democracia/GIIS, 2012), 73.

23 SHELA. Sociedade de História da Educação da América Latina. Lucha por la democracia y formación profesional crítica: El colectivo de reflexión universitaria en la Universidad de Guadalajara. Memoria del X Congreso Internacional de la Sociedad de Historia de la Educación Latinoamericana. Puerto Vallarta: out/2014. 136-153. 
dalgo, membro do Sindicato Único do Pessoal Acadêmico da Universidade Autônoma de Querétaro (SUPAUAQ):

Os diretores de faculdade tiveram de recorrer aos professores por honorários para que a universidade pudesse crescer. De outra forma teríamos um número muito limitado de professores de tempo completo. Não seria o suficiente para cobrir a demanda. [...] Temos 1.600 professores afiliados ao SUPAUAQ. Aqueles que têm tempo livre e completo são afiliados ao sindicato, mas outros 1.500 são contratados por honorários. São professores que não podemos incorporar, ou que terão de esperar muitos anos até poderem se tornar professores de tempo livre e depois de tempo completo ${ }^{24}$.

Na Colômbia estes professores com contratos precários são denominados de catedráticos. O Ministério da Educação Nacional (MEN) da Colômbia informa que em 2012 havia 111.124 professores no sistema de ensino superior - em instituições públicas e privadas - dos quais 33.084 eram de tempo completo, 12.767 de meio período e 65.273 que trabalhavam por hora (catedráti$\cos )$. Quanto à formação dos professores, 5,2\% eram doutores, 22,3\% mestres, $32 \%$ especialistas e $40,5 \%$ graduados ${ }^{25}$. No entanto, devemos salientar que ser professor de "tempo completo" na Colômbia não é sinônimo de contrato efetivo ou estabilidade.

Na Argentina, berço da emblemática Reforma Universitária de Córdoba (1918), havia em 2014 nas 49 universidades nacionais, aproximadamente 100.000 docentes sem estabilidade (mais de $70 \%$ do total) e ainda 30.000 que lecionavam e não recebiam salários, denominados como "ad honoren" ${ }^{26}$. Os "ad honoren" podem chegar a trabalhar durante vários anos até acumularem um "antecedente" que os habilitem a disputar alguma das vagas remuneradas, mas sem estabilidade.

Nas Instituições Federais de Ensino Superior (IFES) do Brasil a figura do professor substituto é minoritária, mas em 2011 o governo Dilma Rousseff editou a Medida Provisória no 525, depois transformada na Lei 12.425 em 17 de junho de 2011, que amplia a possibilidade de contratação desse professor substituto para suprir a expansão desses estabelecimentos de ensino, estabelecendo um limite de vinte por cento do quadro de efetivos. Essa lei, ainda que tenha inicialmente um limite estabelecido aponta para o processo de precarização como dos países citados mais acima, mas em várias universidades estaduais é mais comum que nas federais.

Tais formas de contratação precária eram anteriores à contrarreforma universitária, porém foram estimuladas para reduzir o custo da manutenção das

24 Professor José Luís Álvares Hidalgo, da Universidade Autônoma de Queretáro (UAQ). Concedida a Paiva, Luís, Queretáro.

25 Becerra, Ligia Alba Melo, Jorge Enrique Ramos F. y Pedro Oswaldo Hernández Santamaria. La Educación Superior em Colombia: Situácion Actual y Análises de Eficiencia. Borradores de economía, num.808. (Bogotá: Banco de la Colombia, 2014), 49.

26 Baigorria, Cláudia. Docentes universitarios arrancan el ciclo con una semana de paros. Central de trabajadores de la Argentina. (Buenos Aires), ano X, No.108, mar/2015. 
instituições e também fragmentar a união e resistência dos docentes. A vulnerabilidade do professor advém da ausência de estabilidade. A manutenção do emprego está sujeita a relações de confiança com as autoridades universitárias e maior dependência da indicação dos chamados chefes políticos, com isso, estabelecendo uma relação de perverso clientelismo.

Outro traço comum foi a pressão para que as instituições universitárias ampliassem o autofinanciamento com a adoção de medidas como a cobrança de mensalidades na graduação e pós-graduação, venda de serviços, de consultorias, projetos, pesquisas, oferecimento de cursos pagos, estabelecimento de acordos com empresas, cessão de equipamentos, laboratórios e profissionais, criação de fundações, captação de doações de ex-alunos, ampliação do número de alunos por professor, congelamento de investimento em infraestrutura, etc.

Em 1999 na UNAM os estudantes promoveram uma greve vitoriosa, que se estendeu por um ano, contra a transformação das taxas simbólicas em mensalidades efetivas. Os docentes apoiaram o movimento. Na Colômbia, em 2011, os estudantes levantaram-se contra as intenções do governo de Juan Manuel Santos em alterar a lei do ensino superior. Em 2002 os estudantes da USP protagonizaram uma greve pela contratação de 259 professores. Aulas de Geografia ou História da África eram ministradas em anfiteatros. Depois de 106 dias de movimento conquistaram a contração de 92 docentes.

Na Colômbia e no México o contingenciamento orçamentário impediu a construção de novas universidades e resultou no aumento do número de estudantes por instituição, como nos relata a professora Sara Yaneth Fernández Moreno, da Universidade de Antioquia (UdeA), e ex-presidente da Associação dos Professores da Universidade de Antióquia (Asoprudea) em Medellin:

Nós temos uma planta docente (estrutura e número de cargos) congelada desde 1996. Não se abriram novos cargos. Substituem-se os que vagam, mas não há abertura de novos cargos, desde 1996. Agora eu te digo. Em 1993 eram 18.000 estudantes. Hoje são 40.000. São 35.000 na graduação e 5.000 na pós-graduação. Em 1993 tínhamos um ou dois programas de pós-graduação. Um em Rio Negro e outro em... Bogotá. E agora temos quatorze pontos regionais. Quatorze sedes da UdeA espalhadas pelo país ${ }^{27}$.

Fernandéz acrescenta que em 2015, entre 40\% e $45 \%$ do orçamento da universidade era gerado pela da própria instituição. Conforme Sguissardi (2006, p.1030) também o Brasil vivenciou situação semelhante no período 1994-2002:

[...] o ensino superior público federal teve uma expansão de $37 \%$ nas matrículas e uma redução de $5 \%$ no seu corpo docente e de $21 \%$ no seu quadro

27 Professora Sara Yaneth Fernández Moreno, da Universidade de Antioquia (UdeA). Entrevista Concedida a Paiva, Luís, Medelín. 
de funcionários, além do quase congelamento salarial de docentes e funcionários técnico-administrativos. ${ }^{28}$

A partir do governo de Luiz Inácio Lula da Silva (2003), foram criadas dezenas de instituições e centenas de campus, e promoveu-se a interiorização, mas os recursos destinados à iniciativa privada via o Programa Universidade para Todos (Prouni), e o Fundo de Financiamento Estudantil (FIES), representaram a transferência de bilhões de reais para a iniciativa privada; ainda que tenham permitido que os jovens trabalhadores tivessem acesso ao ensino superior, constituindo a primeira geração em suas famílias vivenciarem essa importante experiência educacional. A previsão de recursos para o FIES em 2016 é de mais de dezoito bilhões de reais, ou 18\% do orçamento do Ministério da Educação (MEC). A expansão das instituições públicas foi insuficiente para alterar a distribuição do número de matrículas entre o setor público e privado.

Na Argentina, onde o acesso ao ensino superior é irrestrito desde 1949 - medida anulada apenas durante a ditadura militar que vigorou de 1976 a 1983 - houve criação de novas instituições universitárias mesmo durante o governo Menem, mas um crescimento significativo, bem como a interiorização das instituições e aumento da participação do ensino superior no Produto Interno Bruto (PIB), só ocorreu a partir da queda do governo da Aliança, em 2001 e da chegada dos Kirchner no poder, em 2003, que logo em 2005 enfrentaram a maior greve dos professores universitários desde 1987. Na paralisação de 2005 os professores lograram a incorporação de todas as gratificações ao salário base.

Recentemente, no ano de 2015, os docentes universitários conquistaram o Contrato Coletivo de Trabalho (CCT). Tratava-se da única grande categoria estatal a não ter essa garantia legal. Um dos pontos estabelece que os docentes possam cursar a pós-graduação gratuitamente, o que resultará na ampliação do número de projetos de pesquisa e na maior qualificação do corpo docente das instituições públicas, porém, muitos professores desconfiam das intenções do governo em cumprir as cláusulas.

\section{CONSIDERAÇÕES FINAIS}

Diante das limitações de espaço não é possível abarcar a diversidade de frentes de atuação que o sindicalismo docente universitário da Argentina, Brasil, Colômbia e México se ocupam na contemporaneidade, como o aten-

28 Sguissardi, Valdemar. Reforma universitária no Brasil - 1995-2006: precária trajetória e incerto futuro. Educ. Soc., Campinas, vol. 27, n. 96 - Especial, p.1021-1056, out. 2006. Disponível em:< http://www.scielo.br/pdf/es/v27n96/a18v2796.pdf >. Acessado em 20/01/2016. 17:03h. 
dimento das demandas individuais de professores (orientações sobre processos, carreira, denúncias, serviços assistenciais) ou grandes temas como as privatizações, as terceirizações; a educação à distância; a apropriação do tempo livre dos professores (trabalho invisível); a reforma trabalhista e previdenciária que atingiu duramente os trabalhadores de todos estes países; a instituição de mecanismos de avaliação que individualizam as possibilidades de ganhos salariais; o produtivismo acadêmico; as formas de mobilização (greves, passeatas, aulas públicas); a dificuldade em lidar com as autoridades universitárias; a luta pela da participação da comunidade universitária nos organismos deliberativos; as publicações sindicais que divulgam pesquisas e questões ligadas à educação ou ao mundo do trabalho.

Destacamos neste texto alguns elementos ligados à gênese e aspectos da contrarreforma que atentaram contra as instituições e a comunidade universitária, mas apesar desse quadro, é necessário destacar o importante papel desempenhado pelas entidades sindicais e o movimento estudantil, e não haveria um texto melhor que do próprio BM reconhecendo o caráter extremamente difícil da reestruturação neoliberal:

No caso das universidades públicas, o corpo de professores conta com meios adicionais para fazer frente às ameaças de mudança radical e perda de empregos: o conceito da universidade como bastião legítimo e necessário da continuidade e tradição; a tradição de liberdade acadêmica, e o exército de alunos atuais, passados e futuros, a maioria dos quais sabem expressar suas ideias de forma convincente e decidida, são politicamente instáveis e, em geral, tendem a somar-se à causa dos que se opõem aos esforços do governo por modificar radicalmente sua universidade ${ }^{29}$.

\section{FUENTES}

Entrevista a Gonzalo Arango Jiménez, professor da Universidade Tecnológica de Pereira (UTP), concedida a Paiva, Luís, Pereira, Colômbia.

Entrevista a Sadi Dal Rosso Professor da Universidade Nacional de Brasília (UnB), concedida a Bauer, Carlos, São Paulo.

Entrevista a José Luís Álvares Hidalgo, Professor da Universidade Autônoma de Queretáro (UAQ), concedida a Paiva, Luís, Queretáro.

Entrevista a Juan de La Cruz Sanchez, Professor da Universidade Nacional (Bogotá), concedida a Bauer, Carlos, Bogotá.

29 Johnstone, D.Bruce, Alka Arora y William Experton. Financiamiento y gestión de la enseñanza superior: Informe sobre los progresos de las reformas en el mundo. Washington, D.C. 1998. Disponível em: < http://wwwds.worldbank.org/external/default/ WDSContentServer/WDSP/IB/2012/11/13/000425962_20121113172945/Rendered/PDF/NonAsciiFileName0.pdf>. Acessado em $10 / 12 / 2015.16: 45 \mathrm{~h}$. 
Entrevista a Sara Yaneth Fernández Moreno, Professora da Universidade de Antioquia (UdeA), Concedida a Paiva, Luís, Medelín.

\section{REFERENCIAS}

Banco Mundial. La enseñanza superior: Las lecciones derivadas de la experiência. Washington: 1995 (versão em espanhol). Disponível em: < http://firgoa.usc.es/ drupal/files/010-1344Sp.pdf>. Acessado em: 05 de mar.de 2015. 23:19.

Baigorria, Cláudia. Docentes universitarios arrancan el ciclo con una semana de paros. Central de trabajadores de la Argentina. Buenos Aires, ano X, nํ108, mar/ 2015.

Basurto, Jorge. Los movimientos sindicales en la UNAM. México D.F.: UNAM/Instituto de Investigações Sociais, 1997. 289.

Becerra, Ligia Alba Melo, Jorge Enrique Ramos F. y Pedro Oswaldo Hernández Santamaria. La Educación Superior em Colombia: Situácion Actual y Análises de Eficiencia. Borradores de economía, num.808. Bogotá: Banco de la Colombia, $2014,49$.

Central Unitária dos Trabalhadores (CUT). Cartaz. Documento iconográfico com denúncia sobre mortes, assassinatos e torturas de militantes sindicais. 2015. Bogotá. Acervo dos autores.

Conadu Historica. Federação Nacional de Docentes, Investigadores e Criadores Universitários. El sindicalismo docente universitario: Aportes a la Reconstrucción colectiva desde CONADU HISTORICA (1971-2011). Buenos Aires: Ediciones Conadu Historica e CTA (Central de Trabalhadores da Argentina), 2011. 149.

Cunha, Luiz Antonio. A universidade temporã: O ensino superior, da Colônia à Era Vargas. 3ed. São Paulo: Editora Unesp, 2007a. 305.

Cunha, Luiz Antonio. A universidade crítica: O ensino superior na república populista. 3ed. São Paulo: Editora Unesp, 2007b. 216.

Donatoni, Alaíde Rita. Trajetória do ANDES: Velho/Novo espaço da educação não formal. Anais do VI congresso luso brasileiro de história da educação. Uberlândia: 17 a 20 de abril de 2006. Disponível in: http://www2.faced.ufu.br/colubhe06/anais/ arquivos/programacaoindividuais8.htm>. Acessado em 20/01/2016. 9:08h.

Gentili, Pablo y Daniel Suárez. Conflitos educacionais na América Latina. Em Gentili, Pablo y Daniel Suárez. (orgs.) Reforma educacional e luta democrática: um debate sobre a ação sindical docente na América Latina. São Paulo: Cortez Editora, 2004. 21-46.

Johnstone, D. Bruce, Alka Arora y William Experton. Financiamiento y gestión de la enseñanza superior: Informe sobre los progresos de las reformas en el mundo. Washington, D.C. 1998. Disponível em: < http://www-wds.worldbank.org/ external/default/WDSContentServer/WDSP/IB/2012/11/13/000425962_201211 
13172945/Rendered/PDF/NonAsciiFileName0.pdf>. Acessado em 10/12/2015. $16: 45 \mathrm{~h}$.

Lechuga, Maria Teresa y Arturo Ramos. Magister Changarrization: los nuevos sujetos académicos y el trabajo precario em la educación superior. 2. ed. México D.F.: STUNAM/Red Tap/Cultura, Trabajo y Democracia/GIIS, 2012.

Leher, Roberto. Reforma Universitária de Córdoba, noventa anos. Um Acontecimento Fundacional para a Universidade Latino-americanista. Disponível in: http:// biblioteca.clacso.edu.ar/ar/libros/grupos/reforAboit/07leher.pdf. Acesso em 06/09/2015 às $17 \mathrm{~h} 31 \mathrm{~m}$.

Ridenti, Marcelo Siqueira. Andes: representação política e sindical de professores universitários. Cadernos de Pesquisa Fundação Carlos Chagas. N.93, pp 72-80. São Paulo, maio 1995. Disponível in:< http://publicacoes.fcc.org.br/ojs/index. php/cp/article/view/851>. Acessado em 20/01/2016. 9:24h.

SHELA. Sociedade de História da Educação da América Latina. Lucha por la democracia y formación profesional crítica: El colectivo de reflexión universitaria en la Universidad de Guadalajara. Memoria del X Congreso Internacional de la Sociedad de Historia de la Educación Latinoamericana. Puerto Vallarta: out/2014, 136-153.

Sguissardi, Valdemar. Reforma universitária no Brasil - 1995-2006: precária trajetória e incerto futuro. Educ. Soc., Campinas, vol. 27, n. 96 - Especial, p.1021-1056, out. 2006. Disponível em:< http://www.scielo.br/pdf/es/v27n96/a18v2796.pdf>. Acessado em 20/01/2016. 17:03h.

Sguissardi, Valdemar. Universidade brasileira no século XXI: desafios do presente. São Paulo: Cortez Editora, 2009, 341.

Valencia, Léon y Juan Carlos Celis Ospina. Sindicalismo asesinado: reveladora investigación sobre la guerra contra los sindicalistas colombianos. Cota: Random House Mondadori, 2012. 253.

\begin{tabular}{l|l|} 
& \\
\hline Bauer, Carlos; Paiva, Luis. “O Sindicalismo docente universitário \\
da Argentina, Brasil, Colômbia, México e sua resistência à \\
contrarreforma universitária". Revista Historia de la Educación \\
Latinoamericana. Vol. 19 No. 28 (2017): 109-128
\end{tabular}




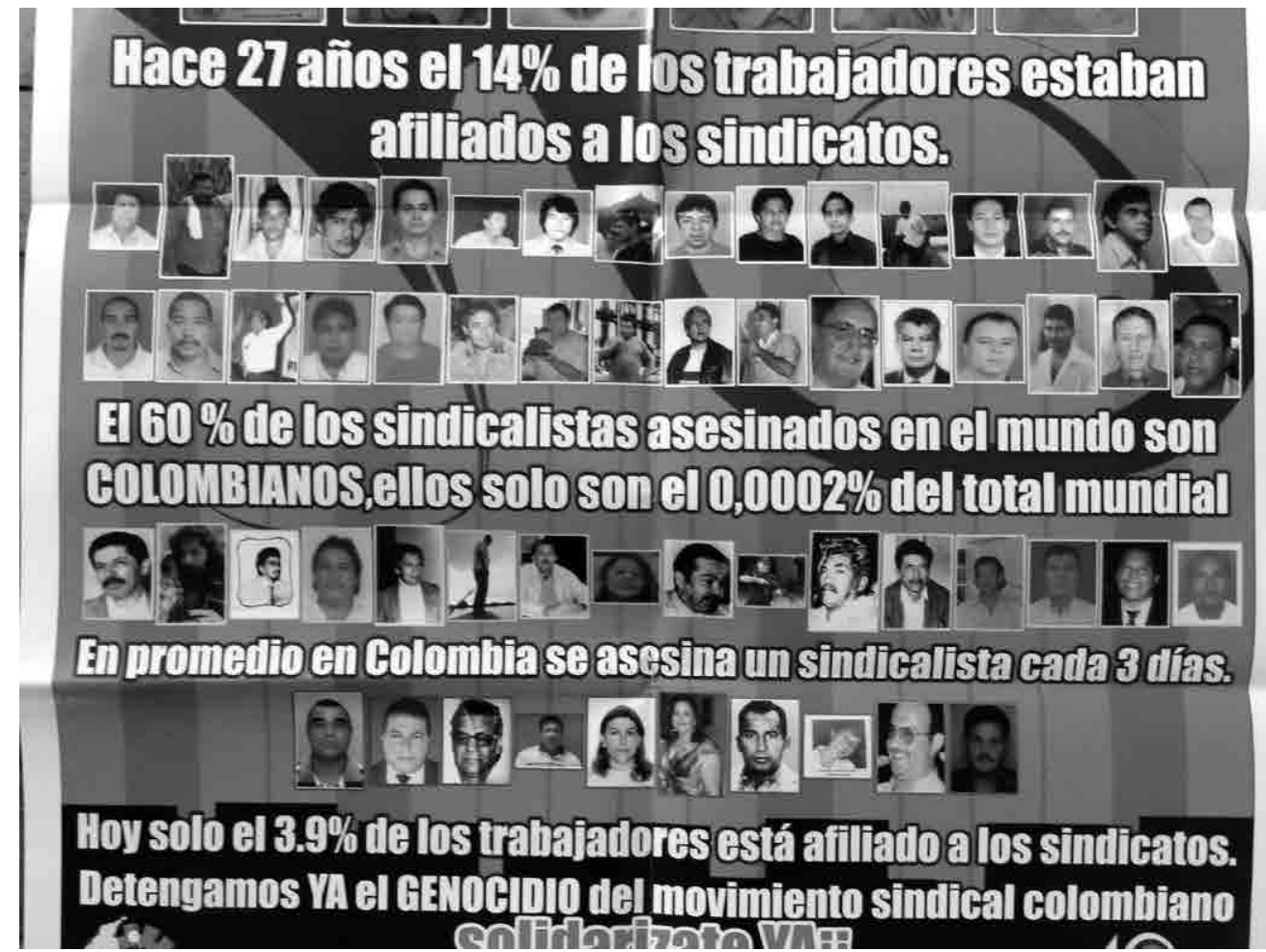

Fuente: Cartaz da Central Unitária dos Trabalhadores da Colômbia, sobre a vitimização do movimento sindical. 